best known isoenzyme change in human neoplasia was described initially by Fishman and his colleague?

\section{Clinicopathological role of tumour index substances in paediatric neoplasia}

A. MUNRO NEVILLE, K. GRIGOR, AND E. HEYDERMAN Unit of Human Cancer Biology, London Branch, Ludwig Institue for Cancer Research, in conjunction with Royal Marsden Hospital, Fulham Road, London SW3 6JB

Oncology has recently entered an exciting new era, one reason for which has been our increasing appreciation of the mechanisms by which many tumour-related phenomena are effected. It is now recognized that human tumours, possibly all human tumours, produce and release a wide variety of different substances (see reviews by Laurence and Neville, 1972; Neville and Cooper, 1976), some of which do not have known metabolic effects. Other products do possess biological and metabolic activity which may account for the metabolic changes observed in patients with neoplasia. However, when such products, with or without metabolic activity, are released into the circulation and other body fluids, this allows them to act as tumour index substances or markers.

These index substances may be tumour-derived when they are produced by the tumour cells themselves or by the tumour stroma. Alternatively, they may be tumour-associated (Neville and Cooper, 1976): for example, the presence of a tumour may, by mechanisms not yet understood, influence liver metabolism and result in the formation and release of a different range or proportion of products from the liver. Such 'tumour-associated' materials may also serve as index substances.

Tumour index substances may be divided into three broad categories, namely, (1) hormones, (2) isoenzymes, and (3) antigens.

Hormones may be either appropriate, such as steroids from an adrenocortical tumour, catecholamines from a phaeochromocytoma or insulin from a $\beta$-cell tumour of the Islets of Langerhans; or they may be inappropriate, of which there are innumerable examples, the commonest possibly being the production of ACTH, ADH or calcitonin by oat-cell carcinoma of the bronchus (Rees and Ratcliffe, 1974; Coombes et al, 1974).

Isoenzyme changes in neoplasia have been known for a very long time and the reversion to fetal isoenzyme forms is particularly well established. The
(1968) and concerns the occurrence of a placental type alkaline phosphatase isoenzyme in the tumouf? and plasma, called the Regan isoenzyme.

Many tumour antigens are not strictly antigen but are referred to as such because they were initially detected as a result of being discovered bj the use of heterologous antisera. On the other handes there are other tumour antigens, correctly named, asthey do evoke cell-mediated and/or humoral immune responses.

The number of 'antigens' which have beer? recognized in tumours has increased rapidly during the past two to three years. The principal group aris the so-called oncofetal antigens which are incorrectly named as they do not generally evoke immune responses in the patient. Examples of oncofeta $\vec{b}$ antigens include the carcinoembryonic antigen (Gold and Freedman, 1965), alpha-fetoprotein (Abelev음 1968), $a_{2} \mathrm{H}$-fetoprotein (Buffe et al, 1970), fetalsulphoglycoprotein antigen (FSA) (Häkkinen anç Viikari, 1969), and the $\beta$-oncofetal antigen ( $\beta$ OFA (Fritsche and Mach, 1975). Materials characteristie of the placenta may also be found in association with neoplasms. Of the placental proteins, the one most studied in relation to tumours has been the $\hat{\theta}_{2} 0$ macroglobulin named the pregnancy-associated macroglobulin (Stimson, 1975). Recent evidence $\overline{9}$ in experimental animals tends to suggest that the 'trư antigens of tumours may also be embryonic in typछ్ and possibly exhibit organ specificity (Baldwin anकू Price, 1975).

Of the ways in which tumour index substances may be important, three are particularly appealing First, they may lead us to understand and explaing many of the signs and symptoms associated witlp. cancer. If the nature and biological effects of these materials can be elucidated, then it may be possible to evolve and design inhibitors of their action ans thereby improve patients' well-being.

Secondly, tumour index substances may have æ. role in the biochemical monitoring of disease. Cur rent evidence suggests that there is no known index substance which will facilitate the earlier diagnosis of primary tumours or their differential diagnosis from non-malignant conditions. However, the use of these materials during the follow-up phase after diagnosis and after surgery may facilitate the earlier detection of metastatic disease than many other methods (Neville and Cooper, 1976).

Finally, those materials may be able to add further dimension to the classification, in particula the functional classification, of tumours and, in addition, may provide the pathologist and cliniciañ with prognostic factors which are important wherp 
the appropriate treatment for individual patients has to be selected.

In this paper, which is in no way intended to be wholly comprehensive, a series of examples of tumour index substances in relation to several paediatric neoplasms shown in table I will be used to illustrate these concepts with particular respect to biochemical monitoring and the functional classification of tumours.

\section{Neuroblastoma}

Neuroblastoma is the third commonest tumour in children (Willis, 1962), occurring predominantly in infancy and early childhood. Sixty per cent occur before the age of 3 years and they are commoner in males than in females. Occasionally, neuroblastoma may be congenital. While neuroblastoma may occur at any site where sympathetic ganglion cells or their precursors are present, $40 \%$ occur in the adrenal glands, particularly the left one. Tumours detected before the age of 2 years are said to carry a better prognosis.

Neuroblastoma is of neural crest origin and may belong to a group of tumours composed of APUD cells (Pearse, 1969). These cell types have been implicated in the inappropriate production of a variety of granule-stored hormones, such as ACTH, calcitonin, insulin, etc. It is thus not surprising to find that neuroblastoma has been associated with Cushing's syndrome and the inappropriate production of ACTH (Symington, 1969). It would be interesting to discover in due course whether or not these tumours can produce other granule-stored hormones such as calcitonin.

Neuroblastoma is known to produce CEA. It was stated initially that all neuroblastomas produced CEA (Neville and Laurence, 1974) but more recent personal studies have shown that that is not so in many patients in the earlier stages; elevated plasma values tend to rise only in the later stages of the disease, a well appreciated phenomenon for tumour index substances in general (Neville and Cooper,

\begin{tabular}{|c|c|c|c|}
\hline \multirow[t]{2}{*}{ Group } & \multicolumn{2}{|c|}{ Index substances } & \multirow[t]{2}{*}{ Tumour } \\
\hline & & Example & \\
\hline Hormones & $\begin{array}{l}\text { Appropriate } \\
\text { Inappropriate }\end{array}$ & $\begin{array}{l}\text { Catecholamines } \\
\text { ACTH }\end{array}$ & Neuroblastoma \\
\hline 'Antigens' & & $\begin{array}{l}\text { CEA } \\
a_{2} \text { HFP } \\
\text { Fetuin-like } \\
\text { AFP }\end{array}$ & $\begin{array}{l}\text { Many epithelial } \\
\text { tumours and } \\
\text { neuroblastoma } \\
\text { Many tumours } \\
\text { Nephroblastoma } \\
\text { Teratoma }\end{array}$ \\
\hline
\end{tabular}

Table I Examples of tumour index substances derived from paediatric neoplasms
1976). Recent evidence tends to suggest that the sequential assay of plasma CEA levels may be of value in monitoring the effects of therapy in neuroblastoma and that rising titres may be detected before the overt development of recurrent or metastatic disease.

Many, if not all, neuroblastomas produce catecholamines or their metabolites, and this property is of great value in monitoring therapy and assisting with the detection of recurrences (Gitlow et al, 1970, 1973; Bond, 1975). Voorhess and Gardner (1962) studied the levels of urinary dopamine, noradrenalin and adrenalin, the metanephrines, and VMA in a series of patients with neuroblastoma and were able to subdivide them into four categories according to the pattern in the urine (table II). Although such a classification may be arbitrary, it is useful in delineating the range of deviations which may occur from normal. Similar studies, conducted by Bell (1963), have shown that patients in group 2 may have a poorer prognosis while those in group 3 have a more favourable outlook.

Approximately $90 \%$ of patients with neuroblastoma have elevated urinary VMA levels; the precise amount does not have any prognostic significance (Bond, 1975). The less differentiated tumours may have higher levels of the dopamine metabolite, homovanillic acid (HVA) (Gitlow et al, 1973). A few patients will not have raised VMA titres. However, abnormal levels of HVA or one of the catecholamine metabolites are almost always found (Gitlow et al, 1970).

A rapid return of the urinary VMA level to normal with therapy is associated with a good prognosis, whereas a persistent elevated level or one which, after being normal, returns into the pathological range is indicative of residual or recurrent disease (Bond, 1974, 1975). Elevated titres have been recorded for up to three years before other overt clinical evidence of neoplasia became apparent.

It would, therefore, appear that the measurement of VMA with/without other catecholamine metabolites of neuroblastoma is adequate to monitor the course of the disease. Recourse to the use of inap-

\begin{tabular}{lllll}
\hline Urinary product & \multicolumn{2}{l}{ Group } & & \\
\cline { 2 - 5 } & 1 & 2 & 3 & 4 \\
\hline Dopamine & E & E & N & N \\
Noradrenalin & E & E & N & N \\
Metanephrine & E & N & E & N \\
VMA & E & N & E & N \\
\hline
\end{tabular}

Table II Urinary excretion pattern of catecholamines and their metabolism in neuroblastoma ${ }^{1}$

${ }^{1}$ After Voorhess and Gardner (1962).

E-elevated; N-normal. 
propriate products, such as CEA or ACTH, is not required.

\section{$a_{2} \mathrm{H}$-Fetoprotein}

$a_{2} \mathrm{H}-F e t o p r o t e i n$, described by Buffe and her colleagues in 1970, can be raised in the plasma of patients with a wide variety of tumours, including many in paediatric practice (table III). Some recent data tend to suggest that $\alpha_{2} \mathrm{H}$-fetoprotein may not in fact be derived from the tumour cells but from their supporting stroma. However, raised plasma titres are a function of the later stages of disease, being seldom present in the earlier stages and hence of little value in differential diagnosis. Rising titres may occur before the clinical detection of recurrent disease, and therefore may be of use in the follow-up phase after diagnosis (Buffe, personal communication).

$\alpha_{2} \mathrm{H}-\mathrm{Fetoprotein}$ is an iron-containing protein, and several iron-containing 'antigens' have been described, including the so-called Order antigen in Hodgkin's disease (Order et al, 1971). Recent studies have shown that both materials are immunologically identical with ferritin, which independently was noted to be raised in the serum of patients with leukaemia and mammary carcinoma (Marcus and Zinberg, 1975). It is not yet clear whether $\alpha_{2} \mathrm{H}$-fetoprotein is chemically identical with ferritin, which appears to exist in multiple molecular forms or isoferritins (Alpert, 1975). Recently, a carcinofetal isoferritin has been described in malignant tissues and fetal liver (Richter and Lee, 1970; Alpert et al, 1973). Normal liver ferritin consists of two subunits, identical in molecular weight but differing in their net charge. Tumour-derived ferritin appears to consist of these two same subunits together with a third acidic subunit. Differing amounts of these subunits may account for the several normal isoferritins and a unique 'tumour-specific' acid isoferritin.

Although this represents a complex chemical

\begin{tabular}{lc}
\hline Disorder & Incidence of positive sera \\
\hline Nephroblastoma & $24 / 27$ \\
Neuroblastoma & $20 / 26$ \\
Teratoma & $14 / 20$ \\
Hepatoma & $19 / 29$ \\
Cholangiocarcinoma & $2 / 5$ \\
Myeloma & $46 / 145$ \\
Lymphoma acute & $26 / 62$ \\
Leukaemia- chronic & $38 / 85$ \\
& $1 / 25$ \\
Cerebral tumour & $15 / 18$ \\
Cirrhosis & $19 / 48$ \\
Controls & $3 / 55$ \\
\hline
\end{tabular}

Table III Serum $a_{2} H$-fetoprotein in various disorders ${ }^{1}$

${ }^{1}$ After Laurence and Neville (1972). problem, each appear to be identical with the others in immunological terms, and this serves to emphasize. the need to make as wide an immunological and chemical search as possible before materials isolate $f_{+}$ from tumours are referred to as 'new' and/o 'antigens'.

\section{Nephroblastoma}

Nephroblastoma is another example of the com moner types of childhood tumours for which nö wholly satisfactory marker substance has yet beew described, although $\alpha_{2} \mathrm{H}$-fetoprotein has been noted? to be elevated in the plasma of some of these patients (table III).

Nephroblastoma-associated mucoproteins, or:acid-mucopolysaccharides, have been reporte $\overrightarrow{\mathrm{d}}$ (Allerton et al, 1970; Morse and Nussbaum, 1967용 Powars et al, 1972) and noted in the serum or urine of some patients lor in their tumour extracts. Suclp changes, however, tend to be found only in advanced disease and they may revert to normal with successe ful chemotherapy and/or surgery. More recently, ख্] fetuin-related material has been isolated from some but not all, nephroblastomas (Wise et al, 1975) and may be the glycoprotein, or a component thereof $\mathrm{f}_{0 \mathrm{O}}$ responsible in part or whole for the previouslos observed plasma and urinary changes. The cellufar and structural heterogeneity and varying degrees $=0$ differentiation of nephroblastomas may account fo the absence of this fetuin-like substance from some tumours if it were to be derived from a particular celp type or from one which had attained a certain stage of differentiation. Burtin and Gendron (1973) have्] also described an 'antigen' associated with nephro 3 blastoma; its relationship to the fetuin-like materia remains to be established, although it has been. claimed that they may be related immunologically (Wise et al, 1975).

The clinical value of these materials remains to be established once they have been purified and sensitivi assay methods have been developed.

\section{Gonadal tumours}

Teratoma is a not uncommon tumour of childhood (Willis, 1962), being commoner in males than in females. In this account data are presented not onlyn from teratoma of children but also of adults to illus+N trate the role of tumour index substances, namely ${ }_{0}^{\omega}$ alpha-fetoprotein and HCG in the management of these tumours and in their functional classification.

Alpha-fetoprotein (AFP) is an oncofetal antigero produced by the fetal liver and by the yolk sac (Abelev, 1968; Gitlin, 1971) which may occur in elevated amounts in the serum of patients with 
primary hepatocellular carcinoma or teratoma (see review by Neville and Cooper, 1976). Raised AFP titres may also occur in urine (Rosenmann et al, 1974).

In our own studies of alpha-fetoprotein in the plasma of patients with gonadal tumours we have found that raised titres do not occur in patients with pure seminomas (Grigor et al, 1975). However, approximately two-thirds of patients with malignant teratomas will show raised values. In many, this is a stage-dependent phenomenon, but raised titres can occur in certain teratomas in association with stage I disease. The demonstration of AFP in, and production by, yolk-sac carcinomas (Nørgaard-Pedersen et $a l, 1975)$ prompted us to review the histology of the tumours previously reported as teratoma.

It became clear that many of the tumours contained yolk-sac structures as the main or sole elements of the tumours and that AFP levels were always raised in such patients (table IV). The remaining teratomas were then subjected to a detailed reassessment after innumerable sections from many more tumour blocks had been cut and processed. Many of the tumours associated with raised serum AFP titres were found to contain small and classical foci of yolk-sac carcinomas (fig 1). In others, the tumour cells had a vacuolated cytoplasm and large pleomorphic vesicular nuclei with one or more prominent nucleoli and tended to form sheets or cords of cells. These undifferentiated areas could, on occasion, be seen to merge with the more typical yolksac elements. It may be, therefore, that those elements also represent a form of yolk-sac tumour but to substantiate this hypothesis it will be necessary to demonstrate by suitable immunocytochemical techniques that AFP is in fact present in, or produced by, these various cell types.

\begin{tabular}{llcr}
\hline Tumour type & \multicolumn{2}{l}{ Serum AFP } & Total \\
\cline { 2 - 3 } & $\begin{array}{l}\text { Normal } \\
(<25 \\
n g / m l)\end{array}$ & Raised & \\
& $n$ & \\
\hline Yolk sac (YS) & 0 & 1 & 1 \\
Teratoma + YS & 0 & 11 & 11 \\
Teratoma + YS + MTT & 0 & 2 & 2 \\
Teratoma + MTT & 2 & 2 & 4 \\
MTT & 3 & 0 & 3 \\
Teratoma & 24 & 35 & 59 \\
Totals & 29 & 51 & 80
\end{tabular}

Table IV Serum AFP levels as a function of the histological type of testicular tumour of 80 patients MTT-malignant teratoma trophoblastic.

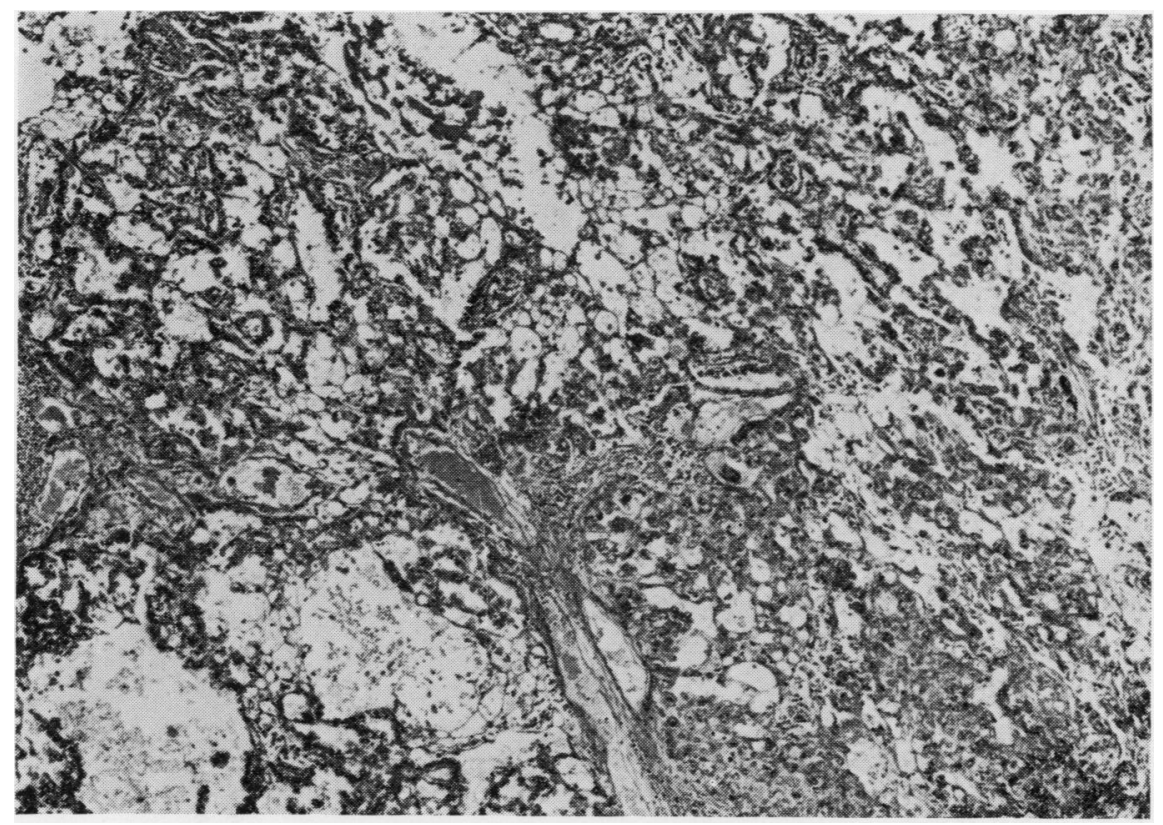

Fig 1 Yolk-sac elements in a testicular teratoma (MTU). This illustration shows a typical yolk-sac carcinoma with irregular acini lined by cuboidal and flattened cells and foci of acinopapillary differentiation. In addition, at the lower right it appears to merge with a more solid undifferentiated area. ( $H$ and $E \times 40)$ 


\begin{tabular}{lc}
\hline Tumour type & Number with raised $\beta H C G$ levels \\
\hline Teratoma & $11 / 32$ \\
MTT & $3 / 3$ \\
Seminoma & $1 / 18$ \\
\hline
\end{tabular}

Table V Serum $\beta H C G$ levels as a function of the histological type of testicular tumour ${ }^{1}$

${ }^{1}$ After Cochran et al (1975).

However, there are still some teratomas associated with raised AFP titres in which no yolk-sac elements can definitely be identified. While other parts of the tumour not sampled may have contained such neoplastic cell types, it is possible that AFP production may arise from other hitherto unrecognized elements.

Many testicular tumours also produce HCG or its $\beta$-subunit (table V) (Cochran et al, 1975). Immunocytochemical techniques capable of localizing HCG in cells have shown that many testicular tumours contain giant-cell types in which HCG is demonstrable. Such cells do not satisfy the present criteria which would entitle a tumour to be referred to as having trophoblast elements, but, again, this observation and approach may be opening up a new method for classifying such cells and the tumours in which they occur.

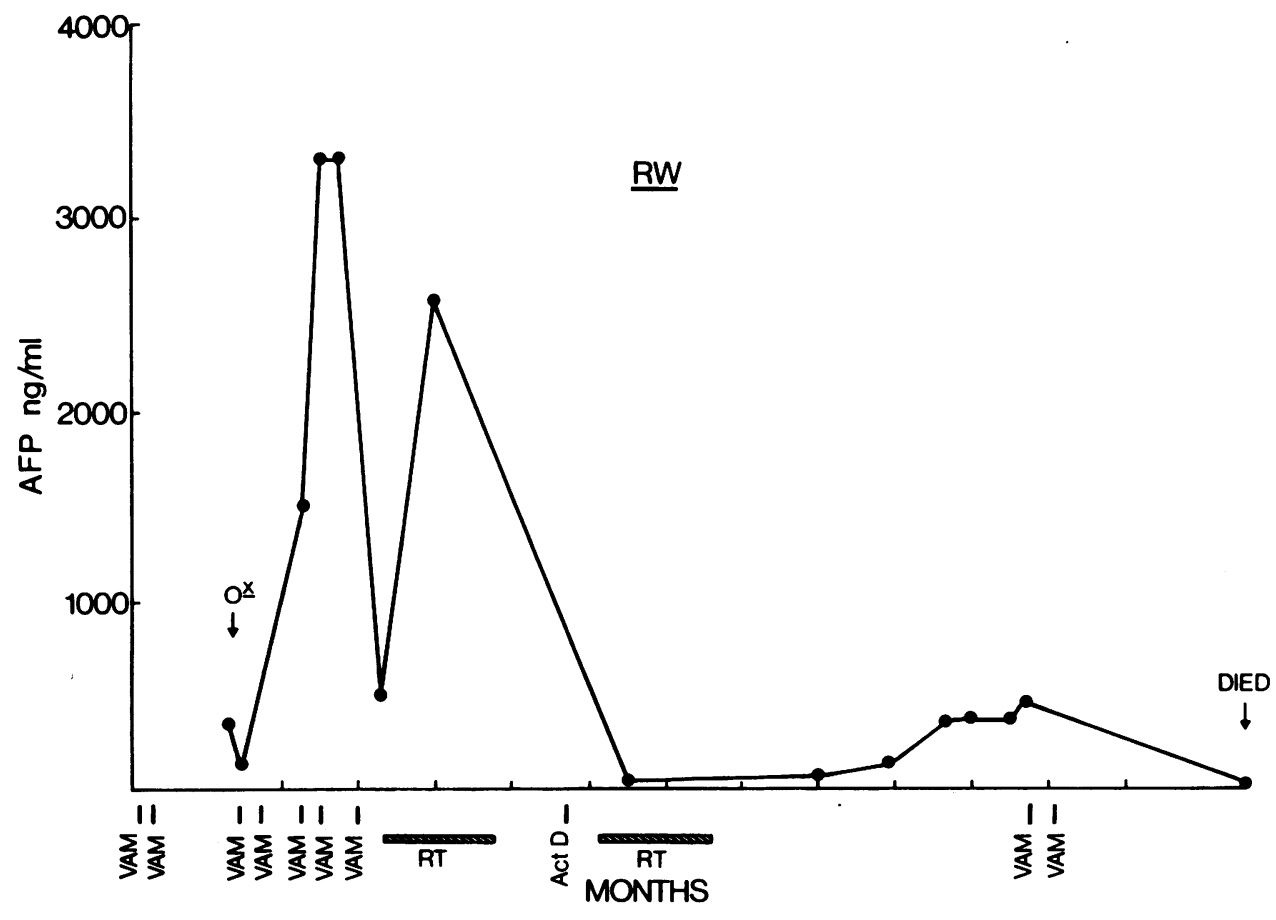

Fig 2 Serum AFP as a therapeutic monitor in a patient RW. The changes in serum AFP are shown as a function of time (months): $O^{x}$-orchidectomy; $R T$-radiotherapy; VAM and Act $D$-course of chemotherapy. titre (table V). Using immunoperoxidase methods, $\underline{\underline{O}}$ Heyderman (1976) found that some seminomas may have atypical giant cells in which HCG is demon- $\stackrel{0}{?}$ strable. Such giant cells thus may not be reactive in type but be neoplastic giant cells and of possible trophoblast origin. When both HCG and $a$-feto- $\frac{\bar{s}}{\bar{Q}}$ protein are raised in the serum, the prognosis is much $\stackrel{\mathbb{Q}}{\square}$ worse than when either is raised alone. An AFPproducing teratoma seems to carry a worse prognosis $\overrightarrow{0}$

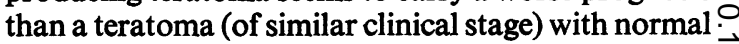
AFP values.

Serum alpha-fetoprotein levels may be of value to $\stackrel{D}{S}$ monitor the course of disease (fig 2). In this patient, $\frac{0}{0}$ the plasma AFP levels rose shortly after orchidec-i tomy due to the evolution of metastases and fell to normal after a successful course of chemotherapy and $\cdot \overrightarrow{-}$ radiotherapy. Later, rising titres were again detected $\vec{D}$

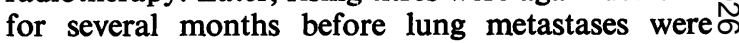
detectable radiologically. A further course of음 chemotherapy resulted in the values falling to nor- mal. However, radiological evidence showed at this $Z$ time progressive tumour growth. While the original biopsy showed the presence not only of teratomatous 3 but also of yolk-sac elements, at necropsy, despite an extensive search, only teratomatous elements were $\overrightarrow{\overrightarrow{0}}$ found in the metastatic tumour. This case serves 80

\section{A. Munro Neville, K. Grigor, and E. Heyderman}

One case of seminoma had an elevated $\beta$-HCG 
illustrate that AFP can be used to monitor the progress of disease and therapeutic responses and togive a forewarning of recurrent disease. However, it can be inadequate on its own due to a dissociation between its level and tumour progression, as has been noted before by Braunstein et al (1973) and Nørgaard-Pedersen (1976). This deficiency can be overcome in part by the concurrent assay of plasma HCG or $\beta$-subunit levels.

It appears therefore that for AFP and HCG, or its $\beta$-subunit, measurement in the serum or demonstration in tissue sections will be of value in achieving a much more rational and complete classification of those tumours and may be of value as prognostic indices. Finally, both may be of value in assessing therapy and also in monitoring the follow-up phase to detect recurrences before their discovery by other diagnostic means.

\section{Conclusions}

All the current evidence suggests that the measurement of tumour index substances in the blood will not facilitate the earlier detection of tumours or their differential diagnosis from non-malignant diseases. Elevated plasma or serum values are stage-dependent and are, therefore, of value predominantly in the follow-up phase, assisting with the earlier detection of recurrent or metastatic disease. If these deficiencies are to be overcome, it will be necessary to follow the example of endocrinology and develop more dynamic tests or production and secretion rates for tumour index substances. It is equally important, in all such studies, to use well-characterized materials and to examine the properties of any tumour-derived material found in future to ensure that it is not already a known substance and thereby avoid spurious claims of new antigens and much fruitless study. For histopathologists, tumour index substances may provide the means of achieving a classification of tumours based upon functional parameters, thereby giving a new insight into cellular function.

\section{References}

Abelev, G. I. (1968). Production of embryonal serum a-globulins by hepatomas: review of experimental and clinical data. Cancer Res., 28, 1344-1350.

Allerton, S. E., Beierle, J. W., Powars, D. R., and Bavetta, L. A. (1970). Abnormal extracellular components in Wilms' tumor. Cancer Res., 30, 679-683.

Alpert, E. (1975). Characterization and subunit analysis of ferritin isolated from normal and malignant human liver. Cancer Res., 35, 1505-1509.

Alpert, E., Coston, R. L., and Drysdale, J. W. (1973). Carcinofoetal human liver ferritins. Nature (Lond.), 242, 194-196.

Baldwin, R. W. and Price, M. R. (1975). Neoantigen expression in chemical carcinogenesis. In Cancer. 1. A Compre- hensive Treatise, edited by F. F. Becker, pp. 353-383. Plenum Press, New York and London.

Bell, M. (1963). In The Clinical Chemistry of Monoamines, edited by H. Varley and A. H. Gowenlock, p. 82. Elsevier, Amsterdam, London and New York.

Bond, J. V. (1974). Catecholamine excretion levels in neuroblastoma (Letter). Brit. med.J., 3, 574.

Bond, J. V. (1975). Clinical features of neuroblastoma. Brit. J. Hosp. Med., 14, 543-554.

Braunstein, G. D., McIntire, K. R., and Waldmann, T. A. (1973). Discordance of human chorionic gonadotropin and alpha-fetoprotein in testicular teratocarcinomas. Cancer (Philad.), 31, 1065-1068.

Buffe, D., Rimbaut, C., Lemerle, J., Schweisguth, O., and Burtin, P. (1970). Présence d'une ferroprotéine d'origine tissulaire, l' $a_{2} \mathrm{H}$ dans le sérum des enfants porteurs de tumeurs. Int. J. Cancer, 5, 85-87.

Burtin, P. and Gendron, M. C. (1973). A tumor-associated antigen in human nephroblastomas. Proc. nat. Acad. Sci. (Wash.), 70, 2051-2054.

Cochran, J. S., Walsh, P. C., Porter, J. C., Nicholson, T. C., Madden, J. D., and Peters, P. C. (1975). The endocrinology of human chorionic gonadotropin-secreting testicular tumors: new methods in diagnosis. J. Urol., 114, 549-555.

Coombes, R. C., Hillyard, C., Greenberg, P. B., and MacIntyre, I. (1974). Plasma-immunoreactive-calcitonin in patients with non-thyroid tumours. Lancet, 1, 1080-1083.

Fishman, W. H., Inglis, N. R., Green, S., Anstiss, C. L., Gosh, N. K., Reif, A. E., Rustigian, R., Krant, M. J., and Stolbach, L. L. (1968). Immunology and biochemistry of Regan isoenzyme of alkaline phosphatase in human cancer. Nature (Lond.), 219, 697-699.

Fritsche, R. and Mach, J-P. (1975). Identification of a new oncofoetal antigen associated with several types of human carcinomas. Nature (Lond.), 258, 734-737.

Gitlin, D. (1971). Sites of alpha-fetoprotein synthesis (Letter). New Engl.J. Med., 285, 1436-1437.

Gitlow, S. E., Bertani, L. M., Rausen, A., Gribetz, D., and Dziedzic, S. W. (1970). Diagnosis of neuroblastoma by qualitative and quantitative determination of catecholamine metabolites in urine. Cancer (Philad.), 25, 1377-1383.

Gitlow, S. E., Dziedzic, L. B., Strauss, L., Greenwood, S. M., and Dziedzic, S. W. (1973). Biochemical and histologic determinants in the prognosis of neuroblastoma. Cancer (Philad.), 32, 898-905.

Gold, P. and Freedman, S. O. (1965). Demonstration of tumor-specific antigens in human colonic carcinomata by immunological tolerance and absorption techniques.J. exp. Med., 121, 439-462.

Grigor, K. M., Detre, S. I., Laurence, D. J. R., Stevens, U., and Neville, A. M. (1975). Comparison of plasma carcinoembryonic antigen and alpha-fetoprotein in various tumours (Letter). Lancet, $2,412$.

Häkkinen, I. and Viikari, S. (1969). Occurrence of fetal sulphoglycoprotein antigen in the gastric juice of patients with gastric diseases. Ann. Surg., 169, 277-281.

Heyderman, E. (1976). Personal communication.

Laurence, D. J. R. and Neville, A. M. (1972). Foeţal antigens and their role in the diagnosis and clinical management of human neoplasms : a review. Brit. J. Cancer, 26, 335-355.

Marcus, D. M. and Zinberg, N. (1975). Measurement of serum ferritin by radioimmunoassay: results in normal individuals and patients with breast cancer. J. nat. Cancer Inst., 55, 791-795.

Morse, B. S. and Nussbaum, M. (1967). The detection of hyaluronic acid in the serum and urine of a patient with nephroblastoma. Amer.J. Med., 42, 996-1002.

Neville, A. M. and Cooper, E. H. (1976). Biochemical monitoring of cancer. A review. Ann. clin. Biochem., 13, 283-305. 
Neville, A. M. and Laurence, D. J. R., eds. (1974). Report of the Workshop on the carcinoembryonic antigen (CEA): the present position and proposals for future investigation. Int.J. Cancer, 14, 1-18.

Nørgaard-Pedersen, B. (1976). Personal communication.

Nørgaard-Pedersen, B., Albrechtsen, R., and Teilum, G. (1975). Serum alpha-foetoprotein as a marker for endodermal sinus tumour (yolk sac tumour) or a vitelline component of 'teratocarcinoma'. Acta path. microbiol. scand., 83A, 573-589.

Order, S. E., Porter, M., and Hellman, S. (1971). Hodgkin's disease: evidence for a tumor-associated antigen. New Engl.J. Med., 285, 471-474.

Pearse, A. G. E. (1969). The cytochemistry and ultrastructure of polypeptide hormone-producing cells of the APUD series and the embryologic, physiologic and pathologic implications of the concept. J. Histochem. Cytochem., 17, 303-313.

Powars, D. R., Allerton, S. E., Beierle, J., and Butler, B. B. (1972). Wilms' tumor clinical correlation with circulating mucin in three cases. Cancer (Philad.), 29, 1597-1605.

Rees, L. H. and Ratcliffe, J. G. (1974). Ectopic hormone production by non-endocrine tumours. Clin. Endocr., 3, 263-299.

Richter, G. W. and Lee, J. C. K. (1970). A study of two types of ferritin from rat hepatomas. Cancer Res., 30, 880-888.

Rosenmann, E., Okon, E., Zaitchek, G., Dishon, T., and Boss, J. H. (1974). In Alpha-Feto-Protein: Proceedings of the International Conference, edited by R. Masseyeff, p. 345. Inserm, Paris.

Stimson, W. H. (1975). Variations in the level of a pregnancyassociated a-macroglobulin in patients with cancer.J. clin. Path., 28, 868-871.

Symington, T. (1969). Functional Pathology of the Human Adrenal Gland, pp. 127-130. E. and S. Livingstone, Edinburgh.

Voorhess, M. L. and Gardner, L. I. (1962). Studies of catecholamine excretion by children with neural tumors. $J$. clin. Endocr., 22, 126-133.

Willis, R. A. (1962). The Pathology of the Tumours of Children, pp. 7-17. Oliver and Boyd, Edinburgh and London.

Wise, K. S., Allerton, S. E., Trump, G., Powars, D., and Beierle, J. W. (1975). A fetuin-like antigen from human nephroblastoma. Int. J. Cancer, 16, 199-210.

\section{Aetiological factors in childhood neoplasia}

C. L. BERRY ${ }^{1}$ Department of Pathology, Guy' Hospital Medical School, London Bridge SEF̂s 9RT

In considering possible aetiological factors in the causation of the solid tumours of childhood it is necessary to keep in mind a number of epidemio? logical facts. Some of the tumours apparently haves their origin in intrauterine life, a number are associated with specific syndromes of somatic. abnormality, and others show distinct familiaf tendencies. Teratomas have distinctive characteris-o tics. A unified hypothesis for tumour induction in ? childhood seems unlikely to fit all observations, and some apparent relationships, for example, thato between teratogenesis and carcinogenesis, need to beD carefully examined. Transplacental carcinogenesis is another important concept, recently shown to be을 relevant in man.

In this review I shall consider some of these prab-के lems and attempt to indicate which fields of study arf likely to be profitable. In 1961 Campbell et al foundo that $65 \%$ of children with malignant disease were beyond medical help when the diagnosis waso established. Since then great strides in treatment have been made, but identification of available predispos- 0 ing factors is obviously important and, in oneo instance (irradiation), may already have proved 3 valuable. Before assessing any factor, however, it is necessary to consider the problems of identifying. potential carcinogens in man. One of the besto descriptions of these difficulties has been given byo Lynch (1969), who points out that the mode, time, and intensity of carcinogenic exposure must be considered in detail and related to host factors, such 3 as age, sex, race environment, occupation culture, 0 geographical site, etc. It is fortunate that many? of these interrelated variables are more readily con-o trolled in studies of children than in adult work.

\section{Radiation}

For some time confident assertions have been made ${ }^{\omega}$ about the role of radiation, particularly in the first trimester, in the genesis of childhood malignancy? (see Stewart and Kneale, 1970). Recently, Oppenheim@

${ }^{1}$ Present address: Department of Pathology, The London Hospital, Whitechapel, London E1. 